\title{
Understanding Early Mathematical Modelling: First Steps in the Process of Translation Between Real-world Contexts and Mathematics
}

\author{
Ángel Alsina ${ }^{1} \cdot$ María Salgado $^{2}$
}

Received: 5 March 2021 / Accepted: 12 October 2021 / Published online: 11 November 2021

(c) The Author(s) 2021

\begin{abstract}
The aim of this study is to provide data to better understand the processes of early mathematical modelling. According to this, an early mathematical modelling activity carried out by 21 Spanish schoolchildren aged 5-6 years is analysed, using the validated tool "Rubric for the Evaluation of Mathematical Modelling Processes" (REMMP). The results show that children link the content of the problem with their prior knowledge (understanding); identify the important data of the problem and simplify it (structuring); show some difficulties in substituting the elements of the real context for mathematical objects (mathematizing); use progressively mathematical objects and strategies in order to propose solutions for the problem (working mathematically); compare the solution with the initial problem (interpretation); justify the proposed model via valid arguments (validation); and also communicate the decisions taken throughout the modelling process and the concrete model obtained applied to the real context (presenting). We conclude that the description of this type of activities and the tools for their analysis could be used for grading and teaching tool in order to promote mathematic modelling in early childhood education.
\end{abstract}

Keywords Early mathematical modelling $\cdot$ Concrete model $\cdot$ Real problems · Rubric $\cdot$ Early childhood education

\section{Introduction}

Different institutions and authors have begun to suggest the need to incorporate mathematical modelling into the early years of education (Alsina et al., 2021b; Alsina \& Salgado, 2021; English, 2006, 2010; English \& Watson, 2018; English \&

\footnotetext{
Ángel Alsina

angel.alsina@udg.edu

1 University of Girona, Girona, Spain

2 University of Santiago de Compostela, Lugo, Spain
} 
Watters, 2005; CCSSI, 2010; NCTM, 1989, 2000; Ruiz-Higueras \& García, 2011; Ruiz-Higueras et al., 2013; Shahbari \& Peled, 2017; Suh et al., 2017; ToalongoGuamba et al., 2021, among others), due to its importance in both real-world applications and mathematics education itself. With the aim of distinguishing advanced mathematical modelling from activities which make it possible to generate initial models in early years, in this article, we shall use the term "early mathematical modelling". This term emphasizes initial knowledge in the process of translating between real-world contexts and mathematics, assuming that mathematical modelling is a process which employs mathematics to represent, analyse, make predictions and provide information about the phenomena of the real world (Bliss \& Libertini, 2019; Blum \& Borromeo Ferri, 2009).

This new approach to mathematical modelling applied to the early years does not claim to consider modelling as a collection of isolated themes. In other words, the aim is not to associate mathematical modelling exclusively to the use of manipulative models (physical materials) or graphic and/or visual models (representations) in order to teach contents. Rather, we conceive early mathematical modelling as a process or cycle which, within the framework of the resolution of real problems, helps to create initial models for analysing, explaining and understanding reality, based on a process of reflection which implies constant comings and goings between real contexts and the mathematics used by early year learners (Alsina \& Salgado, 2021).

The literature describes modelling cycles in various ways, because they are dependent on various directions and approaches of how modelling is understood and, in some cases, if complex or non-complex tasks are used. Borromeo-Ferri's (2006) focus lies on the view of various modelling cycles with respect to the aspects of the differentiation of real situation (RS), situation model (SM) respectively mental representation of the situation (MRS), real model (RM) and mathematical model (MM). The terms situation model (SM) and mental representation of the situation (MRS) are used synonymously. Based on these aspects, she divides the four groups of modelling cycles concerning the first three phases: (1) distinction between situation model (SM)/mental representation of the situation (MRS) and real model (RM); (2) mixed type of SM/MRS and RM; (3) no distinction between SM/MRS and RM; and (4) from real situation (RS) to mathematical model (MM) without distinction in SM/MRS and RM. In the current study, we focus especially on group 1, which consider the cognitive processes of individuals during modelling processes. This is why the situation model is included in this cycle, because it is supposed that this phase is more or less undergone by all individuals during modelling. According to Borromeo Ferri (2006), the well-known term situation model is mainly used in connection with non-complex modelling problems, to be precise, with word problems. A situation model can be described, without going into great detail here, as a mental representation of the situation, which is given in the word problem. From this point of view, we assume the modelling cycle proposed by Blum and Lei $\beta$ (2007), who used the situation model learning on Reusser's approach (1997) and integrated it as new phase in their modelling cycle (Fig. 1). One of the main features of this modelling cycle is that pupils can start from one point of the cycle without the need to follow an established order. It is precisely this coming and going which allows them to progressively perfect the model sought. What is more, as can be seen, in the 


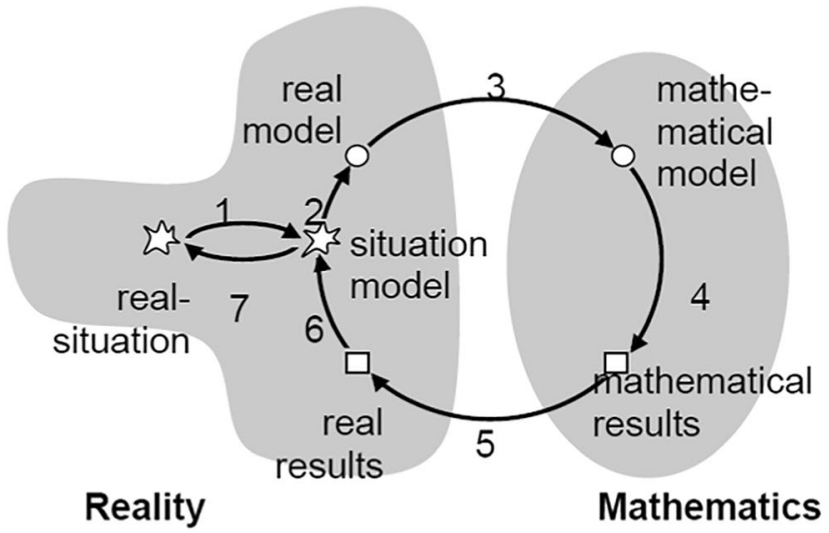

1 understanding the task

2 simplifiying/ structuring

3 mathematizing

4 working mathematically

5 interpretation

6 validation

7 presenting

Fig. 1 Blum and Lei $\beta$ 's mathematical modelling cycle (2007)

final phase, it is important for pupils to socialize the model with their classmates, to gather the relevant observations and to carry out any necessary adjustments with the aim of progressively improving the model. This is a particularly relevant feature in early childhood education, where the processes of interaction, negotiation, dialogue and co-construction of knowledge are very present (Alsina et al., 2021a).

It should be mentioned that, to the present time, there is only a limited number of studies which have analysed the processes of early mathematical modelling from this perspective. Furthermore, in early year mathematics curriculums, there is no approach which deals with the different standards in a transversal way or which implies a process of reflection in the translation process between real-world contexts and mathematics (Trelles-Zambrano \& Alsina, 2017). This panorama has negative repercussions on the pedagogical knowledge of mathematics teachers of young children, who have lack of opportunities in promoting mathematical modelling processes via real problems.

With the purpose of generating an inflection point, this study aims to advance the understanding of early mathematical modelling and to offer specific guidelines and tools to teachers of the initial stages of education. In order to achieve this goal, the following research question is posed: How can the early mathematical modelling carried out by 5 - and 6 year-old pupils be characterized? To answer this question, the aim of this study is to analyse an early mathematical modelling activity carried out by 21 Spanish schoolchildren aged 5-6 years, based on a real problem. In order to analyse the modelling cycle, we used a previously validated tool in the form of a rubric. This tool has been named "Rubric for the Evaluation of Mathematical Modelling Processes" (REMMP) and includes specific indicators for early childhood education (Toalongo-Guamba et al., 2020). 


\section{Mathematical Modelling in Early Years}

Studies that have begun to analyse mathematical modelling at early years have provided some relevant initial data. For example, Ruiz-Higueras and García (2011) and Ruiz-Higueras et al. (2013) state that 3-6-year-old children can develop modelling processes on complex systems of variation in order to construct their initial numerical knowledge or to establish justified connections between the tangible world and a model thereof, the symbolic regime of which has internal rules with different levels of formalization. Alsina and Salgado (2021) analysed a mathematical modelling activity with 4-5-year-old children based on Blum and Lei $\beta$ (2007) modelling cycle. They conclude that children are capable of generating a model, although they present some deficiencies, particularly in the final phases of the modelling cycle. Subsequently, using the same modelling cycle, Alsina et al. (2021b) compare two early mathematical modelling activities implemented to the same group of children in 3 years and 5 years, respectively, to analyse the skills that they develop to create models. The results show that 3 -year-olds begin to work on various steps of the cycle, such as interpretation, structuring and comprehension and, to a lesser extent, mathematization and mathematical work; however, validation and exposition/presentation are still difficult to achieve. However, in the same group of children, but at the age of 5 years, it can be seen that the first steps of the cycle are reinforced and progress is made in validation and exposition/presentation. Furthermore, they conclude that the cognitive development of children in early childhood education determines their capacity for abstraction, since their thinking is concrete and, consequently, the models they can create are also concrete, which is why they call them concrete models.

Studies with primary children by English (2006, 2010), English and Watters (2005) and English and Watson (2018) indicate that modelling activities make it possible (a) to generate models for resolving a situation; (b) to recognize the limitations generated by the creation of the model and its application; (c) to facilitate the interpretation, organization and operation of data by way of informal inferences; and (d) to acquire knowledge from higher levels of the study plan. Peter-Koop (2009) confirmed that mathematical modelling provides opportunities for children to develop new mathematical knowledge which is higher than that which would correspond to their age. However, in general, she puts forward the idea that mathematical modelling is a tool which goes beyond finding the solution to a specific problem. Suh et al. (2017), examine the experiences of two elementary teachers' implementation of mathematical modelling in their classrooms and how the enactment by the teachers and the engagement by students exhibited their creativity, critical thinking, collaboration and communication skills. From their results, they propose that mathematical modelling provides space for teachers and students to have a collective experience through the iterative process of making sense of and building knowledge of important mathematical ideas while engaging in the critical 21st Century Skills which are necessary in our complex modern world.

In recent decades, some mathematics curricula have begun to incorporate mathematical modelling. In Principles and Standards for School Mathematics 
(NCTM, 2000), it is presented as a notion with different meanings: (a) to refer to the physical materials with which pupils work (manipulative models); (b) to suggest exemplification or simulation, such as when the process of resolving a problem is modelled; and (c) as an approximate synonym of "representation". From this viewpoint, a mathematical model refers to the mathematical representation of the elements and connections in an idealized version of a complex phenomenon. It is also stated that all teaching programs from all stages of education should prepare all pupils to use representations to model and interpret physical, social and mathematical phenomena:

From pre-kindergarten up to level 2 (3-8 years of age), pupils can model how to distribute 24 cookies between 8 children, using tiles or logic blocks in different ways. In stages 3-5 (9-11 years of age), they begin to use representations to model phenomena of the world around them, which helps them to recognize quantitative patterns (...). (NCTM, 2000, p. 75)

As can be observed, the NCTM encourages learners from the age of three to begin to use representations to model phenomena of different natures and, at the same time, attempts to reinforce the idea that the presence of mathematical modelling should increase in subsequent academic levels.

In Common Core State Standards for Mathematics (CCSSM), mathematical modelling is defined as "the use of mathematics or statistics to produce a description (i.e. a model) of a real-world situation and to deduce additional information about the situation by way of calculations and mathematical or statistical analyses" (Common Core Standards Writing Team, 2013, p. 5). In general terms, mathematical modelling receives more attention in the CCSSM than in the NCTM proposal (Hirsch \& McDuffie, 2016; Trelles-Zambrano \& Alsina, 2017). Furthermore, the CCSSM document is clear in stating that modelling should be considered as a process and not as a collection of isolated issues. However, it is evident that it receives no transversal treatment, as there are fields in the different levels of education which do not possess standards relating to a modelling process.

Given its impact in curriculums, the considerations of The International Community of Teachers of Mathematical Modelling and Applications (ICTMA) are also analysed. This organization was set up in 1983 with the aim of promoting the research and teaching of mathematical modelling and its applications in different levels of education, from primary to university education. One factor worthy of mention is that this Community brings together both teachers and professionals of mathematical modelling on a scientific level. Therein lies its strength, as dialogue between mathematicians and mathematics teachers is an increasingly latent need. One relevant aspect of recent meetings has been the construction of a theory making it possible to unify criteria to implement mathematical modelling in the classroom. In this regard, general parameters for the teaching and learning of mathematical modelling have been established (Kaiser et al., 2006, 2011; Stillman et al., 2013, 2015, 2017, 2020): the learning objectives, the fundamental reasons for achieving these objectives in different levels of education, proven ideas on how to support teachers in the implementation 
of learning objectives and the recognized educational challenges and dilemmas relating to different ways of organizing teaching, together with theoretical and empirical analyses of the learning difficulties related with modelling and ideas on different ways of evaluating learning in modelling activities and the related obstacles.

\section{Methodology}

A qualitative study of an exploratory nature was designed (McMillan \& Schumacher, 2001) in order to describe and analyse the modelling process carried out by 21 Spanish schoolchildren of 5-6 years of age, based on a real problem: the pupils acquired the role of apple farmers, and, during the 2-h task, they had to determine criteria for classifying the apples according to their qualitative and quantitative attributes and sell them to different potential buyers. A task such as this is stated as a genuine problem, reflecting a real-world context and shows students when and why someone might need to sort apples. It also prompts students to describe their process, which relates to creating a generalizable model (Peter-Koop, 2009).

\section{Description of the Early Mathematical Modelling Activity "Classifying Apples for Potential Buyers"}

The teacher took apples of different morphological and physical characteristics (size, shape and weight) and of different external appearances (colour, marks or visible defects) to class for the pupils to observe their different characteristics and to take on the role of apple farmers in order to establish different categories and to offer different qualities. In order to do so, a dialogue was established in which the children expressed the similarities and differences which they could observe at first sight. During this dialogue, the teacher posed questions for the pupils to state whether they knew anyone who grew apples, whether all the apples were of the same quality, where they had seen apples of different qualities, etc. Once the dialogue had finished, the teacher proposed the following problem:

You are apple farmers and must classify the apples in your basket for several buyers: high quality gift basket distributors (the "best" apples); supermarkets ("apples which can be sold"); school districts ("smaller apples for lunch"); and the least attractive apples which can be used for making purées and juices. Each group has tools for measuring, weighing... and a blank piece of paper for writing the results. You must classify your apples for the different buyers and then explain how you have decided to classify the apples and why. In order to do this, each group has to prepare a presentation for the other apple farmers in order to help them understand how to classify their apples for potential buyers. In the end, we will bring together all of your explanations.

With this real-world problem, the aim is that each small group can formulate an initial model enabling the apples to be classified according to their qualitative and 
quantitative attributes before concluding by bringing together their ideas in order to refine the model. Thus, the main types of knowledge employed are the development of the habit of working in groups and application; critical sense; personal initiative; curiosity and interest in learning; the development of skills in resolving real problems; the identification and comparison of the characteristics of the apples; the discrimination of concepts of measurement (big, small, heavy, light, etc.); the use of both standard and non-standard units of measurement in real situations; and the description of the problem-solving process, which is related with the creation of a generalizable model. This knowledge is promoted through the mathematical teaching practice of the classroom teacher, which is based on teaching mathematics through mathematical processes (Alsina et al., 2021a; NCTM, 2000): problem solving, reasoning and proof, communication, connections and representation. In this sense, during the modelling activity, the teacher poses questions to promote reasoning and critical thinking, encourages the children to communicate and represent their mathematical ideas, etc.

\section{Data collection}

In order to gather data, the activity was recorded via video and photographs and then transcribed. In addition, the work produced by the pupils (drawings, written texts, etc.) was analysed. In order to record the activity, two adults were present in the class: the teacher and a trainee teacher (pre-service teacher), previously trained in early mathematical modelling. The teacher wore an audio recorder around her neck in order to record the small groups, and a video camera was also used to record the teacher and the whole group. The camera was located in a corner of the room, thus recording the small groups in the room. During filming, the person recording paid attention to what was happening in the room, moving the camera when necessary or zooming in to capture what was happening more effectively. The camera followed the teacher constantly, taking in as many students as possible and zooming in to record teacher-student interactions or to focus on the worksheets when a student or students were explaining something written on them.

\section{Data analysis}

In order to analyse the modelling cycle, we used a previously validated instructional rubric. According to Andrade (2000), an instructional rubric lists the criteria for a piece of work or what counts and can be used both as a marking tool and as a teaching tool. From this point of view, the "Rubric for the Evaluation of Mathematical Modeling Processes" (REMMP) was specially designed for scoring at the level of a group of students interacting during a modelling task and also to guide teachers in the modelling process (Toalongo-Guamba et al., 2020). In this study, the rubric is mainly used to observe children's mathematical modelling.

The REMMP is based on the seven elements of the different phases of the modelling cycle proposed by Blum and Lei $\beta$ (2007). It contains seven components corresponding to each phase of the modelling cycle and different indicators for the 
different education levels from 3 to 18 years of age. For the construction of the indicators, the results of prior studies have been taken into consideration. For example, from an early age, children consider the limitations and scopes of the model obtained and its application (English \& Watson, 2018; English \& Watters, 2005; English, 2006, 2010). It has also been taken into account that the modelling cycle should not serve solely for pupils to find the solution to a problem. Rather, they should develop new mathematical knowledge and create generalizable models (Peter-Koop, 2009), along with the role of mathematical modelling in promoting creativity, critical thinking, collaboration and communication skills (Suh et al., 2017). More generally, the design of the rubric has been based on the educational perspective of mathematical modelling (Kaiser \& Sriraman, 2006), as it pursues pedagogical and disciplinary objectives, both in the structuring of learning processes and in the introduction and development of concepts.

On the other hand, the guidelines for assessment and instruction in mathematical modelling education (COMAP \& SIAM, 2019), along with Fredj (2013) meta-analysis on the main proposals for evaluating mathematical modelling, have also been taken into account.

Table 1 outlines the components and indicators as far as the stages of early years and primary education are concerned, which are the levels in which we situate early mathematical modelling.

With the aim of facilitating the analysis with the REMMP tool, an initial coding of the data transcribed in different episodes was carried out. These episodes were understood as temporal units associated to the different phases of the modelling cycle, in which the central point of the discussion was to resolve sub-activities, making it possible to approach the general solution to the problem. The episodes were distinguished separately by the authors, and discrepancies were subsequently discussed until agreements were reached, according to the procedure established by Ferrer et al. (2014).

In the following we describe our findings based on our research question using the specific early mathematical modelling activity implemented. First, we categorize the data into phases to describe the actions that took place during the modelling cycle. Second, we show the analysis of the modelling cycle through the REMMP.

\section{Task Process}

Five phases are described according to the different moments of the modelling activity. These five phases are linked to the seven phases of modelling cycle proposed by Blum and Lei $\beta$ (2007), which in turn coincide with the seven aspects of the rubric used: phase 1 is motivational for the children; in phase 2, the teacher promotes understanding of the activity so that the children begin to structure their ideas, in accordance mainly with the first two phases of the modelling cycle used; phase 3 is when the children, in teams, mostly carry out the mathematization, mathematical work and interpretation, to generate a concrete model from the real problem proposed; and in phases 4 and 5, the sharing of the models of each team is promoted. In these last two phases, the teacher tries to ensure that, through interaction, negotiation 


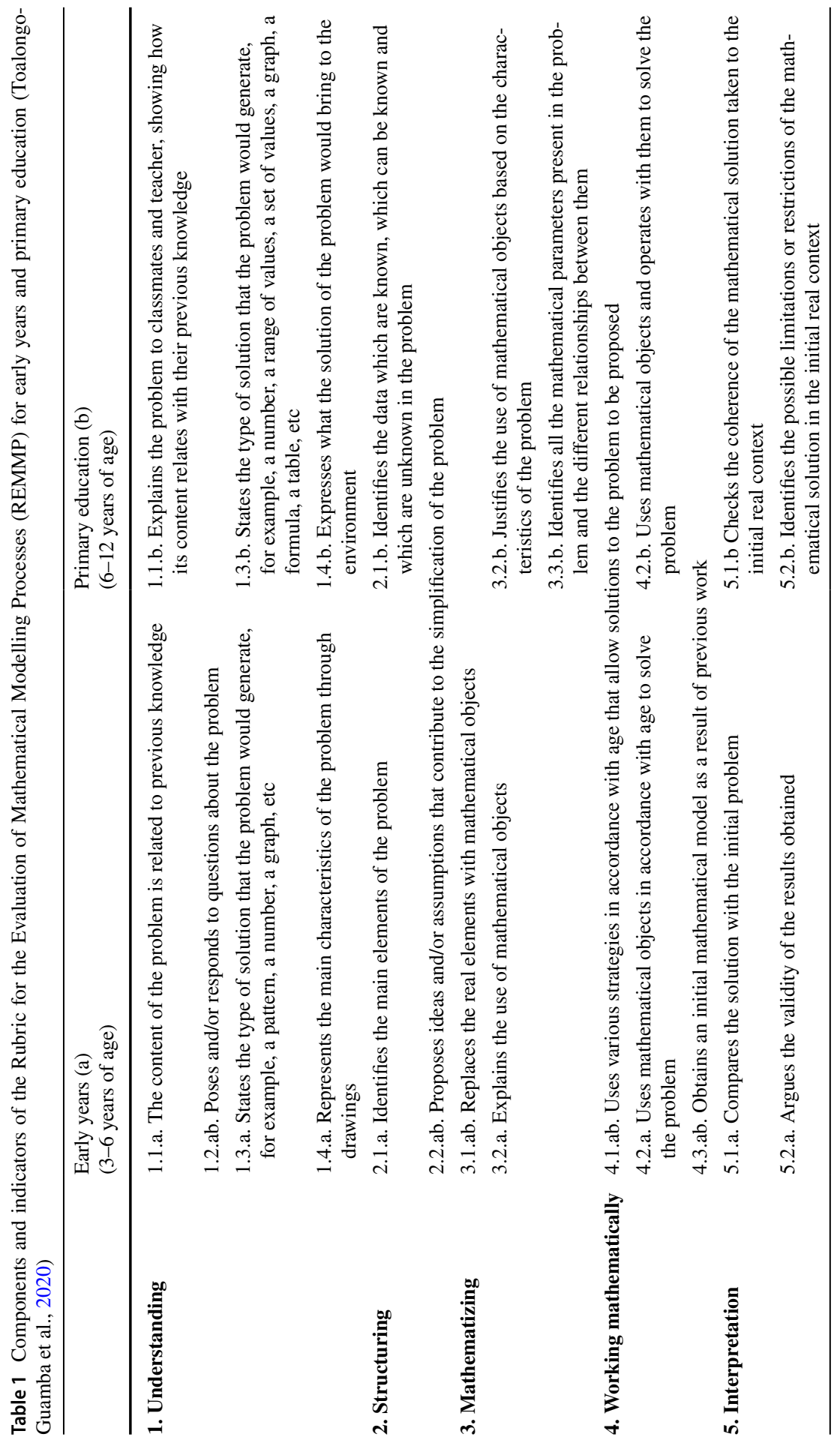




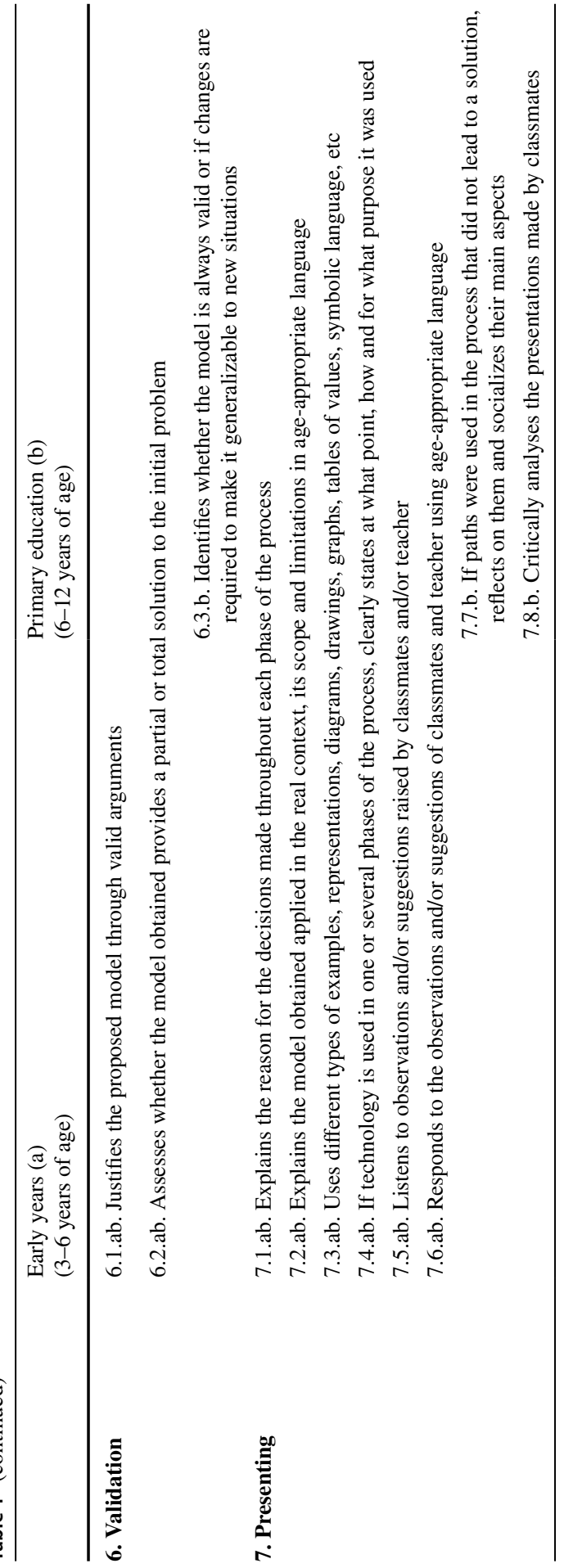


and dialogue, the children create a more refined model that is shared by all. It should be noted that although the teacher is well aware of the modelling cycle, she does not provide students with guidance on how to proceed in each phase but she does carry out the necessary mediation. That is, on the basis of the previous design of the activity and the teaching practice through the mathematical processes, students classify the apples according to different criteria, taking into account that they can start from a point in the cycle without the need to follow an established order, as mentioned in the theoretical framework. Thus, the modelling cycle arises almost naturally in the modelling or problem-solving process.

\section{Phase 1: Watching the Story "Isabella y las manzanas de caramelo"}

The activity begins by watching the story "Isabella y las manzanas de caramelo" ("Isabella and the toffee apples"), which is used as motivation for the topics to be addressed (https://www.youtube.com/watch?v=oBMHP7VkRqw\&ab_channel= PuertoInfanciaJardin). In brief, it tells the story of Isabella, a girl who lives in an apple-producing village. She and her family collect apples in order to sell them at the market. One morning, among the big, small and damaged apples, she found some shiny ones which tasted of toffee.

After reading the story, the teacher mentions the variety of apples and their colours and sizes. She asks some initial questions to encourage all the children to participate, such as "What did Isabella do in the mornings?", "Were all the apples she collected the same?", "How was she surprised one morning?", "Could she sell them at the market?" and "How much would they cost?", to which the children respond according to their own opinions.

\section{Phase 2: Identification and Comparison of the Characteristics of the Apples}

The teacher shows four baskets containing apples of similar characteristics. A dialogue is initiated with the children in which they compare the apples according to their most evident physical characteristics, such as colour and size. In order to encourage the children to think of other possible criteria for classifying the apples, the teacher asks how they can know which apple is the biggest. The pupils begin to respond by saying that they can be compared by measuring, weighing, etc.

\section{Phase 3: Relationships of Equivalence According to the Criteria of Length and Mass}

Four small working groups are created (three groups of 5 children and one of 6 , as there is a total of 21 pupils). The teacher gives each group a basket intentionally containing apples of different qualities and reminds them that they must classify them for sale to several potential buyers: high-quality gift basket distributors (the "best" apples); supermarkets ("apples which can be sold"); school districts ("smaller apples for lunch"); and the least attractive apples which can be used for making purées and juices. Each group has tools for measuring and weighing and a blank piece of paper 
for making a brief presentation explaining how they have classified the apples and why. Subsequently, the process of each group is described in order to formulate an initial model in accordance with the problem posed:

- Green team: They start by weighing each of the apples on digital scales. They identify the numbers but are not aware of the quantity represented by the three figures. Due to their lack of understanding of the numbers and their positional value, they reach a consensus: to begin with, they read the figures on the scales from right to left and vice versa, until one member of the group notices and tells the group that it is always "from here to there", with "here" being left and "there" right, thereby establishing a starting point and an end point as a strategy for knowing the weight of the fruit. However, they then disregard the attribute of weight to classify the apples and, instead, to decide "which apples are of better quality", they take into account their size, stating that "the bigger ones are for luxury hotels" and "the smaller ones are for purees" but do not explicitly discuss those of supermarkets and school canteens.

- Yellow team: To start with, they measure and weigh, register quantities and, in the end, select the length (the perimeter of the apple) for classification, as they agree that they know these quantities and can compare them. In the end, they conclude that "the best ones are these ones because they measure 8 ", "the ones that measure 4 are for juices", "these ones are for the canteen because they measure 5" and "these are for the supermarket because they measure 6" (they refer to $\mathrm{cm}$, although they do not state this orally).

- Blue team: The members divide themselves up, some weigh, and others measure. They measure with rulers and tape measures and weigh with analogical scales. They complete the activity in both cases and gather numerical data which is lacking in apparent meaning. They do not share the data, merely collecting information and not comparing results. In the end, they agree to classify the apples according to their appearance; the discoloured ones for purées and the biggest, shiniest and most attractive ones for hotels.

- Red team: They select the analogical scales. Initially, the children all agree that they must pay attention to the size and, therefore, must weigh the apples. The lack of meaning of the data obtained leads them to use pictorial representations to register the data obtained from the scales: The more the needle turned, the greater the weight. Thus, they classify apples on the basis of their weight, but they do not take into account the number indicated by the analogue scale but the amplitude of the needle in relation to 0 , which could be considered a qualitative rather than a quantitative attribute.

As can be seen, the working groups use different criteria to classify the apples: the green team, based on weight and mainly size; the yellow team, based on weight and mainly length; the blue team, although measuring and weighing, based mainly on appearance; and finally, the red team weighs the apples but classifies them on the basis of their size and, more specifically, according to the amplitude of the analogue balance needle. In general terms, then, it can 
be observed that, although all groups use some quantitative attribute (mainly weight), in several groups qualitative criteria (size and appearance of the apples) predominate. This may be due to the fact that at this age there is a primacy of perception, as Piaget already pointed out (Piaget, 1936, 1947), over other attributes that are not as evident as quantitative ones, which need to be measured indirectly through an instrument such as a scale or a tape measure.

\section{Phase 4: Pooling Information From all of the Teams}

Finally, each small group presented its classification and the criteria chosen. In presenting their ideas, each team justified and argued their process and their results.

\section{Phase 5: Generalization}

The four empty baskets were presented, and the pupils were invited, as apple farmers, to improve the classification and to determine a common criterion for the potential buyers. They were sure that all of them was right and that all of their ideas were good. Therefore, they agreed to make a new classification with all of the contributions of the four teams: (a) the apples for the luxury hotels were the biggest, shiniest, most attractive one and measured 8; (b) the apples for the purées and juices were all marked and measured 4; (c) those for the school canteen were stripes, small and measured 5, so that the children would not feel too full; and (d) those for the supermarket were shiny and measured 6 .

The selection with the contributions of all of the teams was much more refined and selective. Finally, each small group placed its apples in the corresponding basket, checking in case of doubt that it met the general criterion established by the class group.

\section{Results}

We show the analysis of the modelling cycle, involving all the pupils in the classroom, the teacher and a pre-service teacher. As indicated above, a total of 21 pupils aged 5-6 years participate.

In order to carry out the analysis, the components and indicators of the REMMP described in Table 1 (Toalongo-Guamba et al., 2020) have been taken into account. The seven components of the rubric are closely linked to the seven steps of modelling cycle proposed by Blum and Lei $\beta$ (2007).

For the purposes of coding, the term "Child" is used, followed, in all cases, by the initial of the name in order to maintain anonymity. For the adults, the same code is used, albeit without the initials: "Teacher 1" and "Teacher 2", respectively. 
Table 2 Understanding phase

1.1.a. Teacher 1: Child C, were all the apples the same?
1.1.b.
Teacher 1: And what were they like?
Child C: They were shiny.
Teacher 1: Are all apples the same? What are the apples like? Who
can tell me about the apples?
Child C: There are green apples and red apples.
Child E: They grow on trees.
Child A: There are brown and yellow ones.
Teacher 1: Who can tell me anything more about apples?
Child E: They are round.
Teacher 1: Are they all round? Are they all the same?
Child HC: No, small round ones, bigger round ones, like this... (drawing a circle in the air).
Teacher 2: How?
Child HC: Like oranges.
Child Na: No, flatter, like a wheel.
Teacher 1: Why?
Child Na: Because look! Apples aren't so tall or so round. Look at this one, it's squashed on the
1.3.b. It looks like a wheel here, and round here.
Drawings of the food by the 5-6 year-old children, according to size.
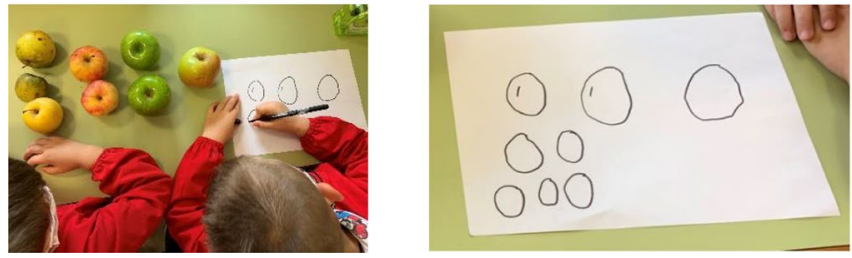

\section{The Understanding Phase}

As can be seen in Table 2, the first step of the modelling cycle proposed by Blum and Lei $\beta$ (2007) is very present in the activity analysed, as practically all the indicators of the first component of the REMMP tool are observed. Specifically, all of the small groups of pupils start to establish links between the problem (classifying the apples for different buyers according to different criteria) and their prior knowledge in such a way as to identify, collaboratively, the main characteristics of the items: colour, shape, size, mass, etc., as can be observed in the transcriptions of indicators 1.1.a and 1.1.b. Furthermore, some pupils formulate questions in order to gain a better understanding of the characteristics of the apples. They do drawings and set out an initial solution to the problem, for example, that the size of the items alone does not determine which are the best; they also have to be attractive (indicators 1.2.ab, 1.3.a and 1.4.a). 
Table 3 Structuring phase

2.1.a Teacher 1: We have a basket of apples. We have to classify them for different types of buyers:

2.1.b luxury hotels, for sale in supermarkets, for school lunches and for making purées. How do you think we can do it?

Child M: First, classify them and then sell them

Teacher 1: What criterion are we going to apply to classify them? Any ideas?

Child N: Attractive ones and ugly ones

Teacher 1: And you, Child G?

Child G: The same

Teacher 1: There are two teams who say that we can classify them by appearance: attractive ones and ugly ones, but that way we have two groups and we need four. What shall we do?

Child N: Less attractive and less ugly, then we have two more

2.2.a Teacher 2: Oh, but that classification depends on each person's tastes. Do we all like the same things?

Child HC: No, by colours

Child NI: The ugly ones are really ugly. I'm sure the hotels won't want them

Teacher 1: Let's think. Can anyone tell me another way to classify them?

Child HC: There are big ones and small ones

Teacher 1: How can we know which ones are big and which ones are small?

Child LC: By measuring them

Child HC: By measuring them we can see which ones are bigger than the others and put them into groups

Teacher 1: What a good idea! Do you know another way?

Child E: No

Teacher 1: If you have two apples, how can you know which one is bigger?

Child NU: Using scales

Teacher 1: Using scales, very good

Child NU: Which one is very fat, which one is fat, less fat and thin

\section{The Structuring Phase}

The actions described in Table 3 show that the second step of the modelling cycle proposed by Blum and Lei $\beta$ (2007) is also present in the activity analysed. On the one hand, some of the actions observed indicate that the children identify the important elements of the problem (indicators 2.1.a and 2.1.b in Table 1). For example, they identify the attributes of the apples in order to start to classify them (colour, appearance, size, etc.), along with other doubtful criteria, such as whether they are shiny and if they have stripes. On the other hand, some contributions were made towards simplifying the problem, such as indicating that the apples can be classified by their weight using scales (indicator 2.2.a).

\section{The Mathematizing Phase}

The components of the REMMP tool corresponding to this phase have been explicitly identified (Table 4), which show the third step of the modelling cycle proposed by Blum and Lei $\beta$ (2007). For example, from the moment that the working groups begin to gather and record the data regarding the length and mass of the different apples, they progressively substitute these items for mathematical objects (numbers and drawings), creating a pictorial representation. On the sheets of paper, 
Table 4 Mathematizing phase

3.1.ab. The pupils record the data of the measurements on the sheet of paper and put the apples which they have already measured to one side:
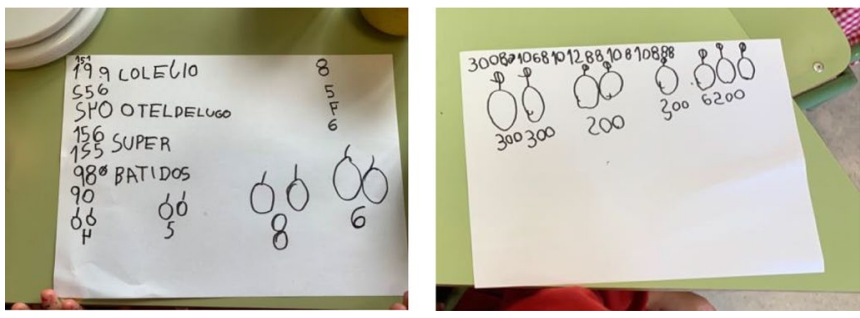

3.2.a Teacher 1: How much does this one weigh?

Child NU: 3.3 with 1 (identifying the numbers on the scales from right to left).

Child C: Grams.

Child E: Not like that, the other way.

Teacher 1; How?

Child E: First the 1, then the 3 and then the 3 grams.

3.2.b. Teacher 1: Why?

Child E: Because it's like this one, and this is $1,3,0$. If they are the same, they have to start the same, with 1.

3.3.b Child N: This one 6, I'll write it down now, this one 6 too.

Teacher 1: And the others were 5. So, which ones are for the canteen?

Child Na: 5, the small ones, and 6 for the supermarket

Teacher 1: Why?

Child Ni: 6 is more than 5 .

Child LC: So, 6 is bigger and 5 is smaller.

they record the data (numbers) of the measurements and explain the meaning, with greater or lesser accuracy depending on their understanding, as is shown in the evidence of indicator 3.1.ab. At the same time, they explain and justify how the results are read on the scales (indicators 3.2.a, 3.2.b and 3.3.b).

\section{The Working Mathematically Work Phase}

In the activity carried out, it is observed how the pupils use different strategies and age-appropriate mathematical objects to take measurements and solve the problem. Thus, for example, they take indirect measurements mainly using the digital scales or the tape measure, even though, in some cases, they do not have control over their use or over the understanding of large numbers. However, they realize that the bigger the number of digits, the higher the number, as is shown in the evidence of the different indicators of this phase (Table 5).

Furthermore, as can be observed in indicator 4.3.ab., some teams propose an initial mathematical model. Thus, as mentioned in the description of the activity, the yellow team formulates an initial generalization, which consists of stating that the greater the result, the bigger the length: (a) with regard to length, when ordering the eight apples, they reach the conclusion that the better quality apples are those with a longer perimeter (the longest ones), and (b) with regard to mass, they conclude 
Table 5 Working mathematically phase

4.1.a Child E: Not like that, the other way

Teacher 1: How?

Child E: First the 1 and then the 3 and then the $3 \mathrm{~g}$

Teacher 1: Why?

Child E: Because it's like this one, and this is $1,3,0$. If they are the same, they have to start with 1

Teacher 1: What are you basing that on? How do you know that?

Child E: (Takes an apple in each hand and answers) My hands tell me

4.2.ab Teacher 2: How do you know it is?

Child NA: Because we put it here (on the ruler) and look how big it is (pointing to the 8)

Teacher 2: And these numbers here? Aren't they important?

Child NA: They're from the scales. It's what the scales said

Teacher 2: And what do they say? What information do they give?

Child LC: How much they weigh

Child NI: The fat ones

4.3.ab Firstly, they order according to the criterion of length:

Child NA: The luxury ones 8 , the ones for the purée 4 , for the supermarket 6 and the canteen 5

Then, according to the criterion of mass:

Teacher 1: Ah, don't you consider the data from the scales?

Child LC: No, they're very big

Teacher 1: Really?

Child LC: There are three numbers

Child NA: Miss, the luxury ones weigh the most because they have the number with the most

figures. They're bigger in every way

Table 6 Interpretation phase

5.1.ab Child E.: Look at them both, they start with the same number and they have three figures

Child NU: They're the same

Child M: The same size. They're the biggest ones

Child C: And then this one is medium

Child NU.: These ones are the small ones, they only have two numbers

5.2.a Teacher 1: So, which weigh more? The apples for the school canteen or for the supermarket?

Child Na: The ones for the supermarket, they are 6

Teacher 1: Why?

Child Ni: 6 is more than 5. The ones for the school are 5

5.2.b Teacher 1: So, if we take an apple for the supermarket, what happens?

Child NI: That it is 6 long

Teacher 3: Why?

Child NA: Because the ones for the supermarket are like that. If it was more, they would be for the luxury hotels

Child LC: And less for the purées and for the schools

that the heaviest ones are better, establishing some relationships between the two aspects. These findings show the presence of mathematical work in the process of mathematical modelling, which is another step in the modelling cycle proposed by Blum and Lei $\beta$ (2007). 


\section{The Interpretation Phase}

The majority of indicators of this phase, which are linked to the fifth step of the modelling cycle proposed by Blum and Lei $\beta$ (2007), have been identified in all of the groups. For example, as is shown in the evidence in Table 6, in the green team, a solution was proposed which consisted of stating that the better quality apples, for the luxury hotels, were the biggest and heaviest ones. This solution was interpreted based on the fact that the greater the size, the more fruit and weight. Some pupils also contribute certain arguments in order to justify the validity of the results. For example, if the numbers are big, it means that they weigh more or that the numbers depend on the size of the apples.

\section{The Validation Phase}

In the sixth step of the modelling cycle (Blum \& Lei $\beta, 2007$ ), all of the groups explain and check their models (indicator 6.1.ab). Furthermore, they evaluate whether they offer a (total or partial) solution for ordering the apples based on length and/or mass or other aspects (6.2.ab), and in some cases they make generalizations (indicator 6.3.b). These justifications and evaluations occur on a micro level, in other words, inside of each group (Table 7).

Table 7 Validation phase

\begin{tabular}{l} 
Teacher 1: Which is the biggest? \\
Child J: This one \\
Teacher 1: Why? \\
Child J: Because it weighs a lot \\
Teacher 1: How much is a lot? \\
Child J: A lot of numbers \\
Child B: The arrow went right to the bottom \\
Teacher 1: And this one? (pointing to a small apple with blemishes) \\
Child B: This one over here, not many numbers, the arrow didn't move much \\
\hline Teacher 1: How did you classify them? Which ones are for the purées? \\
Child NU: The ugly ones, the ones with marks on them \\
Teacher 1: Really? \\
Child E: They are the smallest ones \\
Teacher 1: Why? \\
Child 9I: Because they don't weigh much, two numbers \\
Child NA: We ordered them according to what they measure \\
Teacher 1: Which are for the purées? \\
Child NA: The ones that measure 4, the smallest ones \\
Teacher 1: And for the luxury hotels? \\
Child A: The biggest ones, which measure 8 \\
\hline
\end{tabular}


Table 8 Presenting phase

7.2.a.b (Yellow team)

First of all, they order by the criterion of length:

Child NA: The luxury ones that measure 8 are first. Then the ones for the supermarket, 6 and the ones for the school canteen, 5 . The smallest ones that measure 4 are for the purées

Then, they order according to mass:

Child LC: The biggest ones, which weigh most are for the luxury hotels and the ones which weigh least are for the purées

Child NA: The weight coincides with the length

7.5.ab (Blue team)
Child G: They're ugly, they have little spots, but they can still be used for cooking
Child Y: They can't be thrown away
Child G: They're food, you can't throw food away
(Green team)
Child E: If they fall, you have to eat them quickly because they rot, like flowers. The ones with
spots fell and nobody collected them from the tree because they were damaged
Teacher 1: Which apples do you prefer to sell?
Child NA: The ones for the puré
Teacher 1: Why do you say that?
Child NA: Because there are a lot of them
Teacher 1: A lot? How many are there?
Child HC: Let's count
Child NA: They're going to be able to make a lot of purée, there are a lot of us
Teacher 1: Why are there more for the purée than for the supermarket?
Child NU: Because there are a lot of ugly ones with spots. And the ones for the supermarket
don't have spots and they're not small
Child M: And the ugly ones aren't 6 , they don't measure 6
Teacher 1: Shall we check?
Child M: Get a ruler Miss and you'll see that they aren't 6

\section{The Presenting Phase}

Upon finishing the group work, the pupils are encouraged to socialize as a class group the different strategies employed and the decisions taken by the teams throughout the activity to establish the classifications of the apples according to length, mass or other aspects. In indicators 7.2.ab in Table 8, for example, it is shown how one group explains the criterion used for classifying the apples.

According to Blum and Lei $\beta$ (2007), this presentation on a macro level makes it possible to gather observations and to carry out the necessary adjustments with the aim of progressively improving the model and to make one, more refined, model all together by uniting the contributions of all of the teams, as is shown in the rest of the indicators.

To sum up, the teams of pupils built concrete models which have allowed them to classify the apples according to different criteria. They have also been able to identify certain limitations during the modelling process (e.g. measuring with a ruler is not effective, interpreting numbers with 3 digits on scales, etc.) and have been able to explain how they obtained the results of the problem. Furthermore, they have internalized knowledge about the characteristics of the apples; a bad 
outward appearance does not mean that they cannot be used. Via the presentation of the different models, the children have been able to refine their own model and to create, all together, a single generalizable model in order to classify the apples for the different potential buyers.

\section{Discussion}

In this study, the activity "Classifying apples for potential buyers" has been designed based on Blum and Lei $\beta$ (2007) modelling cycle, and the presence of early mathematical modelling has been analysed based on the REMMP tool (ToalongoGuamba et al., 2020), which is an instructional rubric that can be used both as a grading and teaching tool (Andrade, 2000). As indicated above, the modelling cycle and the REMMP rubric are connected.

The majority of steps of the modelling cycle proposed by Blum and Lei $\beta$ (2007) are present in the early mathematical modelling activity analysed, although in some components of the REMMP tool, difficulties on the part of the pupils have been detected. Particularly, in the mathematical work phase, a lack of experience has been observed in interpreting the result of the measurement with instruments such as scales. These difficulties could also be due to their lack of conceptual understanding (or conceptual misunderstanding) of numbers (reading numbers from $\mathrm{L}$ to $\mathrm{R}$ or $\mathrm{R}$ to L).

In general terms, and without overlooking these difficulties, it can be stated that (Greefrath et al., 2013) the actions of schoolchildren aged 5-6 years interacting during the modelling task have shown that they are capable of generating initial models in accordance with their mathematical knowledge (Ruiz-Higueras \& García, 2011), that they are even able to handle knowledge from higher academic years (English, 2006, 2010; English \& Watson, 2018; English \& Watters, 2005; Peter-Koop, 2009) and that these models can be collectively refined via interaction, negotiation and dialogue, with the mediation of the teacher.

In addition, another relevant aspect to highlight is that, in previous studies, Alsina and Salgado (2021), Alsina et al. (2021b), and Toalongo-Guamba et al. (2021) conclude that the thinking of children in early childhood education is concrete and, consequently, the models they can create are also concrete. However, in this study we have seen that, if children refine their concrete models in the Presentation, they can develop a single generalizable model, improving their capacity for abstraction.

Based on this prior information, early mathematical modelling can be initially characterized as a process which, within the framework of the resolution of real problems, helps to create initial models for analysing, explaining and understanding reality, based on a process of reflection which implies constant comings and goings between real contexts and the mathematics employed by early year pupils. To create these models, which are initially concrete (Alsina et al., 2021b), the following actions are carried out by early childhood students: 
(1) Understanding: they link the content of the problem with their prior knowledge. They pose and/or respond questions about the problem, express the type of solution it would generate, represent the main characteristics and progressively express the problem to their classmates and teacher. In addition, they communicate what the solution contributes to their context.

(2) Structuring: they identify the data of the problem and progressively identify the data which can be known and that which is unknown. Furthermore, they make proposals in order to simplify the problem.

(3) Mathematizing: they can show some difficulties in substituting the elements of the real context for mathematical objects and explain their use, in contrast to the general sub-competencies described by Greefrath et al. (2013). However, they can progressively justify this use based on the characteristics of the problem and identify the mathematical parameters present in the problem and the relations between them.

(4) Working mathematically: they can also use mathematical objects and strategies in order to propose solutions for the problem and to obtain an initial mathematical model. Furthermore, as indicated by Alsina et al. (2021), depending on their age, pupils work with these objects to achieve their aim.

(5) Interpretation: they compare the solution with the initial problem, making the case for the results obtained, and progressively verify the coherence of the mathematical solution taken to the initial real problem, identifying any possible limitations or restrictions..

(6) Validation: they justify the proposed model via valid arguments and evaluate whether it provides a partial or total solution to the initial problem and can identify whether the model is always valid or if it requires changes in order to be generalizable to new situations.

(7) Presenting: finally, they communicate the decisions taken throughout the modelling process and the concrete model obtained applied to the real context, using different language and/or representations depending on their level (drawings, outlines, tables of values, graphs, symbols). Furthermore, they listen to the observations and/or suggestions of their classmates and/or teacher, analysing them critically and responding appropriately. Also, as their level advances, they reflect on the strategies employed when they do not manage to obtain a solution and they socialize it, building more generalizable models.

Another finding of our study focuses on the role of the teachers in promoting mathematical modelling skills. As far as the teacher is concerned, it should be mentioned that significant progress has been observed in the planning and handling of the early mathematical modelling activity in comparison with other preliminary activities which were analysed with the same tool (e.g. Alsina \& Salgado, 2021; Alsina et al., 2021b; Toalongo-Guamba et al., 2021). We attribute this improvement to the professional development with regard to the teachers' experiences in early mathematical modelling activities in the classroom, having a positive impact on the work produced by the pupils. In accordance with Suh et al. (2017), this information shows the importance of the role of the teacher in the implementation of mathematical modelling in the classroom. 
Finally, it should also be mentioned the lack of experience of early years teachers in Spain for carrying out mathematical modelling activities in the classroom. From this perspective, it is necessary to provide tools to help them incorporate mathematical modelling into their classes. For this reason, the design of the REMMP tool fulfils the double purpose of an instructional rubric, in the sense proposed by Andrade (2000): that it will serve teachers as a guide and for evaluation purposes. In the future, it will be necessary to design new studies that analyse the use of REEMP as a marking and teaching tool to contribute to teachers' professional development in early mathematical modelling, as well as identifying similarities and differences between this rubric and other tools or techniques used from different theoretical frameworks.

\section{Conflict of Interest}

The authors declare no competing interests.

Acknowledgements Not applicable

Funding Open Access funding provided thanks to the CRUE-CSIC agreement with Springer Nature.

Open Access This article is licensed under a Creative Commons Attribution 4.0 International License, which permits use, sharing, adaptation, distribution and reproduction in any medium or format, as long as you give appropriate credit to the original author(s) and the source, provide a link to the Creative Commons licence, and indicate if changes were made. The images or other third party material in this article are included in the article's Creative Commons licence, unless indicated otherwise in a credit line to the material. If material is not included in the article's Creative Commons licence and your intended use is not permitted by statutory regulation or exceeds the permitted use, you will need to obtain permission directly from the copyright holder. To view a copy of this licence, visit http://creativecommons.org/licen ses/by/4.0/.

\section{References}

Alsina, Á., \& Salgado, M. (2021). Introduciendo la Modelización Matemática Temprana en Educación Infantil: Un marco para resolver problemas reales [Introducing early mathematical modeling in early childhood education: A framework for solving real problems]. Modelling in Science Education and Learning, 14(1), 33-56. https://doi.org/10.4995/msel.2021.14024

Alsina, Á., Maurandi, A., Ferre, E., \& Coronata, C. (2021a). Validating an instrument to evaluate the teaching of mathematics through processes. International Journal of Science and Mathematics Education, 19, 559-577. https://doi.org/10.1007/s10763-020-10064-y

Alsina, Á., Toalongo-Guamba, X., Trelles-Zambrano, C., \& Salgado, M. (2021b). Desarrollando habilidades de modelización matemática temprana en Educación Infantil: un análisis comparativo en 3 y 5 años [Developing early mathematical modeling skills in early childhood education: A comparative analysis in 3 and 5 years]. Quadrante, 30(1), 74-93. https://doi.org/10.48489/quadrante.23654

Andrade, G. H. (2000). Using rubrics to promote thinking and learning. Educational Leadership, 57(5), 13-18.

Bliss, K., \& Libertini, J. (2019). What is mathematical modeling? In S. Garfunkel \& M. Montgomery (Eds.), Guidelines for assessment \& instruction in mathematical modeling education (pp. 7-21). Consortium for Mathematics and Its Applications and Society for Industrial and Applied Mathematics. 
Blum, W., \& Borromeo Ferri, R. (2009). Mathematical modelling: Can I be taught and learn? Journal of Mathematical Modeling and Application, 1(1), 45-58.

Blum, W., \& Lei $\beta$, D. (2007). How do students and teachers deal with modelling problems? In C. Haines, P. Galbraith, W. Blum, \& S. Khan (Eds.), Mathematical modelling: Education, engineering and economics (pp. 222-231). Woodhead Publishing Limited.

Borromeo-Ferri, R. (2006). Theoretical and empirical differentiations of phases in the modelling process. ZDM, 38(2), 86-95.

Common Core Standards Writing Team. (2013). Progressions for the Common Core Standards in Mathematics (draft) High School, Modeling. Institute for Mathematics and Education, University of Arizona.

Common Core State Standards Initiative [CCSSI]. (2010). Common core state standards mathematics. National Governors Association Center for Best Practices; Council of Chief State School Officers.

Consortium for Mathematics and its applications [COMAP] and Society for industrial and applied mathematics [SIAM]. (2019). Guidelines for assessment \& instruction in mathematical modeling education ( $2^{\text {nd }}$ ed.). (S. Garfunkel, \& M. Montgomery, Edits.) Philadelphia.

English, L. D. (2006). Mathematical modeling in the primary school: Children's construction of a consumer guide. Educational Studies in Mathematics, 63, 303-323.

English, L. D. (2010). Young children's early modelling with data. Mathematics Education Research Journal, 22(2), 24-47.

English, L. D., \& Watson, J. (2018). Modelling with authentic data in sixth grade. ZDM, 50, 103-115.

English, L. D., \& Watters, J. J. (2005). Mathematical modelling in the early school years. Mathematics Education Research Journal, 16(3), 58-79.

Ferrer, M., Fortuny, J. M., \& Morera, L. (2014). Efectos de la actuación docente en la generación de oportunidades de aprendizaje matemático [Effects of teaching activity on the generation of mathematical learning opportunities]. Enseñanza De Las Ciencias, 32(3), 385-405.

Fredj, P. (2013). Modes of modelling assessment-a literature review. Educational Studies in Mathematics, 84(3), 4113-4438.

Greefrath, G., Kaiser, G., Blum, W., \& Borromeo Ferri, R. (2013). Mathematisches modellieren - Eine Einführung in theoretische und didaktische Hintergründe [Mathematical modeling - An introduction to theoretical and didactic backgrounds]. In R. Borromeo Ferri, G. Greefrath, \& G. Kaiser (Eds.), Mathematisches Modellieren für Schule und Hochschule. Theoretische und didaktische Hintergründe (pp. 11-37). Springer Spektrum.

Hirsch, C., \& McDuffie, A. (2016). Annual perspectives in mathematics education 2016: Mathematical modeling and modeling mathematics. National Council of Teachers of Mathematics.

Kaiser, G., Blomøj, M., \& Sriraman, B. (2006). Towards a didactical theory for mathematical modeling. ZDM, 38(2), 82-85.

Kaiser, G., Blum, W., Borromeo Ferri, R., \& Stillman, G. (Eds.). (2011). Trends in teaching and learning of mathematical modelling. Springer.

Kaiser, G., \& Sriraman, B. (2006). A global survey of international perspectives on modelling in mathematics education. Zentralblatt Für Didaktik Der Mathematik, 38(3), 302-310.

McMillan, J. H. \& Schumacher, S. (2001). Research in Education. A conceptual introduction $5^{\text {th }}$ edition. Pearson.

National Council of Teachers of Mathematics [NCTM]. (1989). Curriculum and evaluation standards for school mathematics. Author.

National Council of Teachers of Mathematics [NCTM]. (2000). Principles and standards for school mathematics. Author.

Peter-Koop, A. (2009). Teaching and understanding mathematical modelling through Fermi-Problems. In B. Clarke, B. Grevholm, \& R. Millman (Eds.), Tasks in primary mathematics teacher education: Purpose, use and exemplars (pp. 131-145). Springer.

Piaget J. (1936). La Naissance de L'intelligence Chez. L'enfant [The birth of intelligence in children]. Delachaux et Niestlé.

Piaget, J. (1947). The psychology of intelligence. Routledge.

Reusser, K. (1997). Erwerb mathematischer Kompetenzen. In F. E. Weinert \& A. Helmke (Eds.), Entwicklung im Grundschulalter (pp. 141-155). Beltz.

Ruiz-Higueras, L., \& García, F. J. (2011). Análisis de praxeologías didácticas en la gestión de procesos de Modelización Matemática en la Escuela Infantil [Analysis of didactic praxeologies in the management of mathematical modeling processes in childhood education]. Revista Latinoamericana De Investigación En Matemática Educativa, 14(1), 41-70. 
Ruiz-Higueras, L., García, F. J., \& Lendínez, E. M. (2013). La actividad de modelización en el ámbito de las relaciones espaciales en la Educación Infantil [Modeling activity in the field of spatial relations in Early Childhood Education]. Edma 0-6: Educación Matemática en la Infancia, 2(1), 95-118.

Shahbari, J. A., \& Peled, I. (2017). Modelling in primary school: Constructing conceptual models and making sense of fractions. International Journal of Science and Mathematics Education, 15, 371-391.

Stillman, G. A., Blum, W., \& Biembengut, M. S. (Eds.). (2015). Mathematical modelling in education research and practice: Cultural, social and cognitive influences. Springer.

Stillman, G. A., Blum, W., \& Kaiser, G. (Eds.). (2017). Mathematical modelling and applications: Crossing and researching boundaries in mathematics education. Springer.

Stillman, G. A., Kaiser, G., Blum, W., \& Brown, J. P. (Eds.). (2013). Teaching mathematical modelling: Connecting to research and practice. Springer.

Stillman, G. A., Kaiser, G., \& Lampen, C. E. (Eds.). (2020). Sense-making in mathematical modelling and applications educational research and practice. Springer.

Suh, J. M., Matson, K., \& Seshaiyer, P. (2017). Engaging elementary students in the creative process of mathematizing their world through mathematical modeling. Education Sciences, 7, 62. https://doi. org/10.3390/educsci7020062

Toalongo-Guamba, X., Alsina, Á., Trelles-Zambrano, C., \& Salgado, M. (2021). Creando los primeros modelos matemáticos: Análisis de un ciclo de modelización a partir de un problema real en Educación Infantil [Creating the first mathematical models: Analysis of a modeling cycle from a real problem in Early Childhood Education]. CADMO, Giornale Italiano di Pedagogia Sperimentale, 1, 81-98. https://doi.org/10.3280/CAD2021-001006

Toalongo-Guamba, X., Trelles-Zambrano, C., \& Alsina, Á. (2020). Design, construction and validation of a rubric to evaluate mathematical modeling in school education. Manuscript submitted for publication.

Trelles-Zambrano, C., \& Alsina, Á. (2017). Nuevos Conocimientos para una Educación Matemática del S. XXI: Panorama internacional de la modelización en el currículo [New knowledge for a mathematical education of the XXI century: International panorama of modeling in the curriculum]. UNIÓN, Revista Iberoamericana de Educación Matemática, 51, 140-163.

Ángel Alsina Full Professor of Mathematics Education at the University of Girona (Spain). His lines of research are focused on the teaching and learning of mathematics in the early ages and the training of mathematics teachers. He has published numerous scientific articles and books on mathematical education issues and has carried out multiple activities of permanent training of mathematics teachers in Spain and Latin America.

María Salgado Early years teacher at multilingual school in Sigüeiro (Oroso). Associate Professor of Mathematics Education in the Faculty of Education Sciences at the University of Santiago de Compostela (Spain). Graduate in Musical Education and Mathematics. Doctor in Mathematics Education. Her lines of research include mathematics in early ages and numerical thinking. 